\title{
DOES LEAD PAINT FROM THE SYDNEY HARBOUR BRIDGE CAUSE SIGNIFICANT POLLUTION TO AREAS NEARBY?
}

\section{INTRODUCTION}

There are growing concerns about environmental lead and its potential hazard to human health as it may cause damage to nervous and renal systems. Several studies have investigated the extent of lead contamination by measuring concentrations in the soil. The Australian guideline for further investigation of a site is set at $300 \mathrm{ppm}^{1}$. A lead-soil survey in the Balmain area in $1988^{2}$ found high soil lead levels, with 68 per cent of the 41 samples having concentrations above the $300 \mathrm{ppm}$ level. More recently the Newcastle Lead Study examined lead concentrations in soil near Boolaroo and Argenton in response to community concerns about lead contamination from a nearby lead smelter ${ }^{3}$; soil lead concentrations found by this study ranged from $8-26,794 \mathrm{ppm}$.

Lead in the soil not only comes from point sources such as lead smelter emissions and structures coated with lead paint, but also from vehicle emissions. Soil lead concentrations due to vehicle emissions are often strongly related to distance from roadway and average daily vehicle densities ${ }^{4}$, and have been found to decrease exponentially with distance from roadway. Concentrations usually fell by at least 50 per cent about 50 metres from the roadway ${ }^{5}$ while most deposition occurred in the first 25 metres $^{4}$.

As a result of publicity about the potential hazard of lead-based paint from the Harbour Bridge contaminating nearby public areas during routine maintenance ${ }^{6}$, the Northern Sydney Area Public Health Unit decided to carry out a soil lead survey. The study's objectives were to determine the soil lead concentrations under and adjacent to the bridge on the northern side where lead from vehicle emissions and possibly lead paint would be found. The study also sought to compare these concentrations with those taken close to the major roadway feeding traffic across the bridge. This area is out of range of lead paint contamination from the bridge so the soil sampled would be subject to lead only from vehicle emissions.

\section{METHODS}

We consulted with both the Hunter Area Public Health Unit and the Central and Southern Sydney Public Health Unit on sampling procedure. Soil was sampled using an auger to loosen it and a stainless steel cutting piece to enclose the sample at a depth of five centimetres. Soil from park, reserve and footpath areas was sampled, with each having a degree of grass coverage. Grass coverage was removed before sampling and samples were not taken from garden areas that had been cultivated because of the possibility of contamination with imported soil. Samples were sent to Hampson and Associates' laboratories in Newcastle for testing for lead concentration.

In keeping with the study's objectives eight sites were sampled under or adjacent to the Harbour Bridge near Bradfield Park, Milsons Point (sample group A). A further four sites were sampled further north,

\section{FIGURE 2}

SOIL-LEAD STUDY SAMPLING SITES IN NORTH SYDNEY, MILSONS POINT AND NEUTRAL BAY, 1991.

(Sample site numbering corresponds with that used in Table 5).

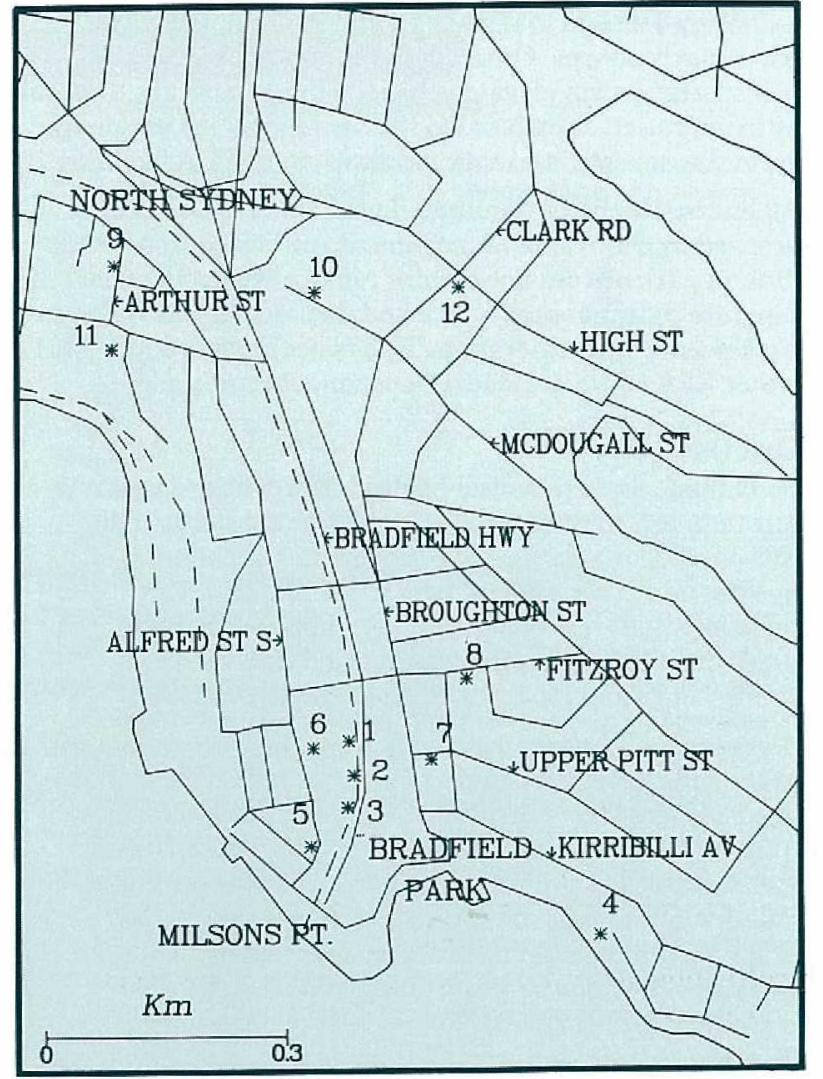

adjacent to a major freeway in the North Sydney and Neutral Bay areas (sample group B). Sampling was carried out between November 4 and 14, 1991 and the locations of sample groups $\mathrm{A}$ and $\mathrm{B}$ are shown in Figure 2.

In group A four samples were taken from different points in Bradfield Park as it is beneath the Harbour Bridge and is a public area. The other three samples in group A were taken at distances up to 350 metres from the park.

In group B the sites tested are north of the bridge within a 50-300 metre range from the Warringah Freeway at North Sydney. The sites varied in their distance from a major roadway so as to test the effect of distance from roadway on the lead concentration found. We were unable to get soil samples less than 50 metres from the Warringah Freeway because the areas examined were either concrete or bitumen, made up of recent fill for road construction, or were garden areas which may have contained imported soils.

A Mann-Whitney test was used to compare the results of sample groups $\mathrm{A}$ and $\mathrm{B}$.

\section{RESULTS}

In group $\mathrm{A}$ the concentrations ranged from $19 \mathrm{ppm}$ to $1,451 \mathrm{ppm}$, with four of the seven samples being 
TABLE 5

SAMPLE SITES AND RESULTS OF SOIL-LEAD TESTING BY PHU 1991

\begin{tabular}{|cclcc|}
\hline SAMPLE GROUP & SAMPLE NUMBER & LOCATION & LEAD CONC. ppm & DIST. FROM ROADWAY \\
\hline Sample group A & 1 & Bradfield Park, first pylon northern end & 1,145 & 10 to 100 metres \\
\hline & 2 & Bradfield Park, middle pylon & 1,306 & 10 to 100 metres \\
\hline & 3 & Bradfield Park, near cricket pitch & 1,097 & 10 to 100 metres \\
\hline & 4 & Dr Mary Booth Reserve & 77 & 350 metres \\
\hline & 5 & Reserve near Paul and Alfred Sts & 1,451 & 100 metres \\
\hline & 6 & Bradfield Park, adj Alfred St South & 318 & 100 metres \\
\hline & 7 & Footpath cnr Pitt and Broughton Sts & 136 & 200 metres \\
\hline Sample group B & 8 & Footpath cnr Fitzroy St and Robertson Lane & 19 & $250-300$ metres \\
\hline & 9 & Footpath cnr Middlemiss and 6 Arthur St & 870 & $50-100$ metres \\
\hline & 10 & Footpath McDougall St (freeway end) & 404 & 100 metres \\
\hline & 11 & Clark Park & 216 & $200-250$ metres \\
\hline
\end{tabular}

over 1,000ppm (Table 5). Each of the four highest concentrations had been sampled about 100 metres or less from the Bradfield Highway. The two lowest concentrations were found in the samples taken at the greatest distance from the highway.

The concentrations found in group $B$ ranged from $216 \mathrm{ppm}$ to $1,269 \mathrm{ppm}$. The $1,269 \mathrm{ppm}$ concentration found in group B is high considering it is about 300 metres from the Warringah Freeway. Further investigation showed that High Street has a high traffic flow and is close to a number of busy roadways associated with the freeway. This would possibly expose the area to additional lead deposition from vehicular emissions.

We found no significant difference between soil lead concentrations found under, or in close proximity to, the Harbour Bridge and those found in group B further north. The median values for group A and group B were $707.5 \mathrm{ppm}$ and $637 \mathrm{ppm}$ respectively $(\mathrm{p}=0.93)$.

\section{DISCUSSION}

The Roads and Traffic Authority (RTA), which maintains the Harbour Bridge, informed us no removal of lead-based paints from the northern end of the bridge has taken place since 1990 because of construction of the Sydney Harbour tunnel. This means it is unlikely there has been any major lead contamination from this source. Nevertheless if lead paint were a major contaminant of the soil as a result of maintenance of the bridge over the past 60 years we would have expected to find significantly higher lead levels under or adjacent to the bridge. A preliminary study has shown that the presence of lead paint flakes in soil will probably produce soil lead concentrations of more than $4,000 \mathrm{ppm}^{7}$. The RTA has taken steps to minimise the potential spread of lead dust that may occur during bridge maintenance and is continuing research in this area.

The similar concentrations of lead in soil (after allowing for the effect of distance) found in areas near the Harbour Bridge and further north near the freeway suggest vehicle emissions are the most important source of lead. The northern sample area is out of range of any possible paint particle fallout from the bridge.

\section{CONCLUSION}

We conclude that the risk of lead poisoning in the Bradfield Park area is relatively low and is similar to areas in similar proximity to a major roadway. The RTA is acting responsibly to ensure possible lead contamination from bridge paint is kept to a minimum. We would recommend that research be continued into finding ways of ensuring bridge maintenance workers and the public are not exposed to the potential hazard from old lead paint on bridges.

John Skinner, Medical Geographer

Reg Baxter, Environmental Health Officer

Erin Farnbach, Biostatistician

Donald Holt, Director of Public Health,

Northern Sydney Area Public Health Unit

\section{ACKNOWLEDGMENT}

Dr Lyn March, Royal North Shore Hospital

1. Australian and New Zealand Environment Council and National Health and Medical Research Council. Draft Australian Guidelines for the Assessment and Management of Contaminated Sites 1990. 2. Royal Prince Alfred Hospital and Central and Southern Sydney Area Health Service. Environmental lead investigation: an interim report by the Environmental Health Unit. July 1988.

3. Galvin J, Stephenson J, Corbett S. Tackling childhood lead poisoning: the Newcastle Lead Study. NSW Public Health Bulletin, 1991; 2:98-99.

4. Wylie PB, Belı LC. The effect of automobile emissions on the lead content of soils and plants in the Brisbane area. Search $1973 \mathrm{Vol} 4$; No 5:161-162.

5. Broadbent JA, Cranwell I. Faunal Studies for the proposed Mount White-Kariong-Ourimbah sections of the Sydney-Newcastle Freeway (No. 3). Environmental and Urban Studies Report No. 45. Macquarie University Centre for Environmental Studies, 1979.

6 . Price T. Bridge paint poison threat: lead base a silent killer. North Shore Times October 231991.

7. Personal Communication with the RTA. 